\title{
Water as a natural and an artistic resource
}

\author{
M. G. Bachmann \\ Faculdade de Arquitectura da Universidade Técnica de Lisboa Pólo \\ Universitário, Alto da Ajuda 1349-055 Lisboa, Portugal
}

\begin{abstract}
The history of the water supply in Lisbon includes some great works of note such as the "Aqueduto das Águas Livres" (1748), the Aqueduct of the Free Waters, a remarkable work of hydraulic engineering, which was the first great achievement to solve the chronic lack of water in Lisbon. The "Reservatório da Mãe d'Água" (1834), the Reservoir Mother of Water was a huge water cistern built to receive and distribute the water directed through the Aqueduct of the Free Waters, which supplied water to Lisbon. Water is one of the most important natural resources; the sustainable management of water resources is a major global challenge. The United Nations Environment Programme is implementing or participating in several environmental assessments. Fresh water, in its consumable condition, represents less than $1 \%$ of the quantity of water on our planet. It is indispensable to study the superficial and subterranean water resources, taking into consideration the cycle of the water, its quality and use. Democratic societies and developed technologies have the added responsibilities of promoting sustainable development to provide rational and efficient management of the water resources. The Water Museum has become a unique place to stimulate art, encouraging the preservation of heritage and education for sustainable development. On the 3rd July, Manuel Carmo's installation "In Definition - The corridor of water in life" confirmed the strong relationship that exists between human beings and water. On 12th July, "Mother of Water" returned to its usual condition, filled again with water. Manuel Carmo, a remarkable artist, sculptor and painter, as well as a poet devoted to aesthetic projects, expressed the importance of water as an artistic and natural vital resource.
\end{abstract}

Keywords: water is life, nature conservation, sustainable future, water therapy, purification, water inspires arts. 


\section{Introduction}

Very little remains of the Roman dam of the III century B.C, situated in Belas and built to supply drinking water to the city of Olissipo. The water supply to the city was always deficient. Francisco d'Olanda, in 1571, in his work "From the source that dies near the city of Lisbon" [1] recommended to the king D. Sebastian, the reuse of the Roman aqueduct, as a way of reducing the lack of water in Lisbon. A painter and a humanist Francisco d'Olanda, an example of the Portuguese Renaissance, wrote a book where he illustrates the situation in the city of Lisbon, considering solutions for some of its urban problems at the time, for example, the water supply:

"Lisbon [...] where everybody that drinks water, does not have more than a strait source for so many people [...] and must bring the water far from Lisbon, where the Romans had brought, from underneath the land, underground piercing many mounts, with much expense and work." [1].

This lack of water dragged on for centuries, leading to an unbearable situation. The first great accomplishment to resolve the problem was the construction of the Aqueduct of the Free Waters, a notable work of hydraulic engineering that enabled the supply of sources and fountains situated in several areas of the city.

We must bring special attention to the Kings' Fountain of the XVII Century, in Alfama, where the residents had to stand in a queue according to their social status, in front of each of the six taps [2].

Work on the Aqueduct of the Free Waters, a project of the engineer Manuel da Maia, commenced in 1732, but was not completed until 1748. In spite of the improvement of the water supply through this monumental aqueduct, a shortage of water hampered the city of Lisbon. The lack of structures caused the deficiencies to become more serious and determined the distribution of water by the "water sellers", who were supplying households through jugs or barrels, the price of which changed in accordance with the availability of water.

The history of the water supply to the city of Lisbon includes some great works of note, such as the Aqueduct of the Free Waters - "Águas Livres" (1748) which was the first big achievement to solve the systematic lack of water in Lisbon. This remarkable work of hydraulic engineering was put into disuse in the 1960s.

The Reservoir called Mother of Water - "Reservatório da Mãe d'Água", in Amoreiras (1834) was built to receive and distribute the water transported through the Aqueduct of the Free Waters; it supplied water to Lisbon from the 18 th century and was later shut down and integrated in the Museum's patrimony.

The Patriarchal Reservoir (1864), an important infrastructure of this period, provided the water distributed into the lower part of the city of Lisbon and the Barbadinhos Steam Pumping Station (1880), responsible for the water distribution, collected from the Alviela River, to the city of Lisbon. Only after 1880, with the construction of the Barbadinhos Steam Station and the Alviela Aqueduct, was it possible to create an efficient urban water supply to Lisbon [3]. 


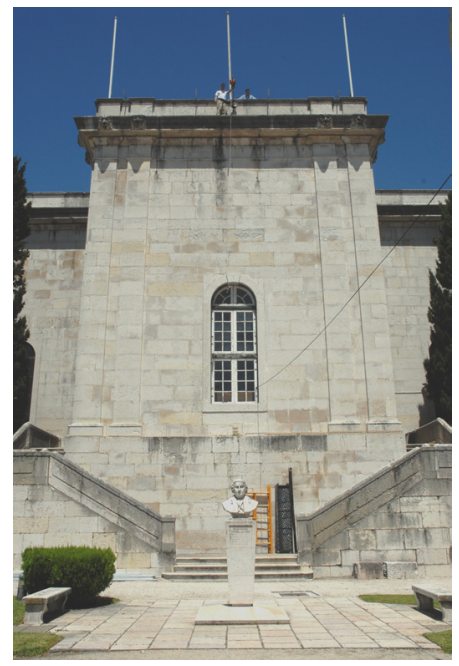

Figure 1: $\quad$ The Mother of Water Reservoir.

The enterprise that nowadays manages the water supply system to Lisbon and to the "Vale do Tejo" area integrates three subsystems: Castelo do Bode with a daily production of $500000 \mathrm{~m}^{3}$; the Tagus Aqueduct with a daily production of $400000 \mathrm{~m}^{3}$; and Alviela, with a daily production capacity of about $50000 \mathrm{~m}^{3}$.

From these three subsystems, the biggest and the most relevant is the one at Castelo de Bode, which currently supplies approximately $60 \%$ of the production capacity needed.

\section{Water is essential for life}

Water is one of the most important resources nature offers to man, and can be found on our planet in different physical states: liquid, solid and gaseous; it has different forms: on the earth's surface, and underground, water may be salty, sweet, or stagnant. Water is a precious resource that needs rational management.

Portugal was one of the European countries without serious water deficiencies, although the regional distribution was quite irregular. Over the last few years, our country suffered a significant increase in the consumption of water, due to the growth of economic activities, new populations, and the improvement of the supply system.

The clean water represents less than $1 \%$ of the quantity of water of our planet and it is distributed very unequally. It is essential that a study of the hydric surface and underground resources be performed, taking into account the cycle of the water, its quality and use. Water is important to man, for drinking and cooking, for hygiene and good health, and recreation. The quality of water is as important as its availability. Water is an endangered resource, since there are threatening consequences caused by the pollution of the water both for public health and for the balance of the ecosystems. 


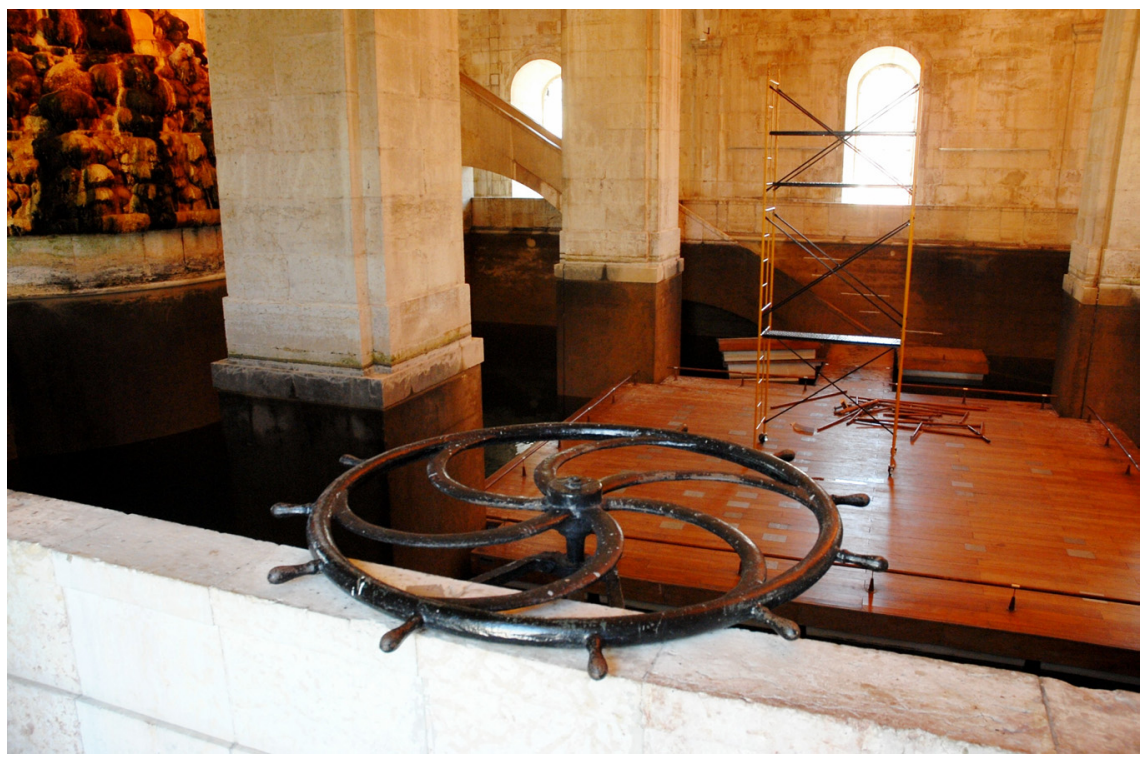

Figure 2: The first part of the art installation, this handle triggers the opening system and the water gradually comes out from the reservoir.

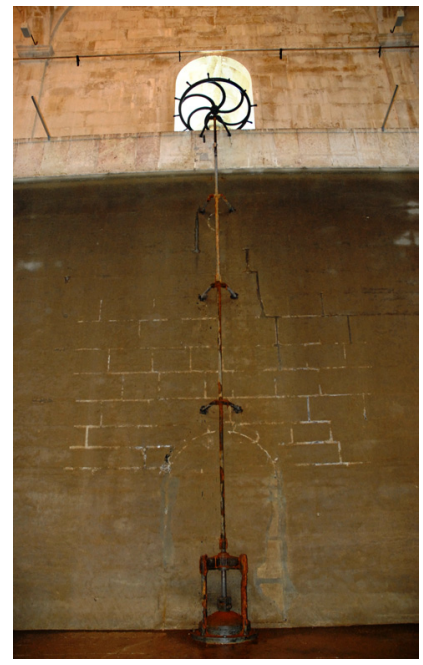

Figure 3: The mechanical system including the handle that puts the giant escape valve into operation. Now the reservoir has no water inside.

The water's analysis in Portugal reveals pollution of the main water sources, caused mainly by agriculture, industry, transport, and domestic activities. In the case of the underground waters, the principal source of pollution is agriculture, not only because of the use of unsuitable processes of irrigation, but also because 
of the excessive application of chemicals such as: fertilizers, pesticides and weed killers. Consequently, while contaminating the ground, these products infect the underground waters through the process of infiltration [4].

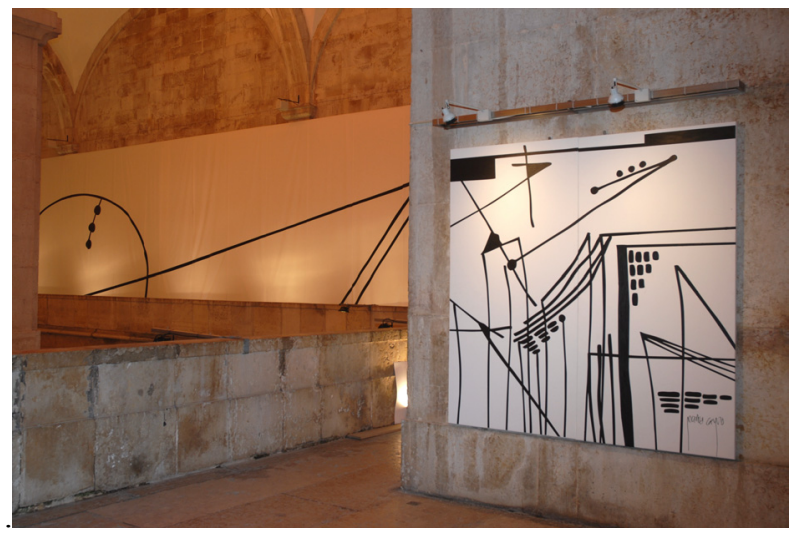

Figure 4: The art installation at the main entrance and at the corridor around the tank "reservoir".
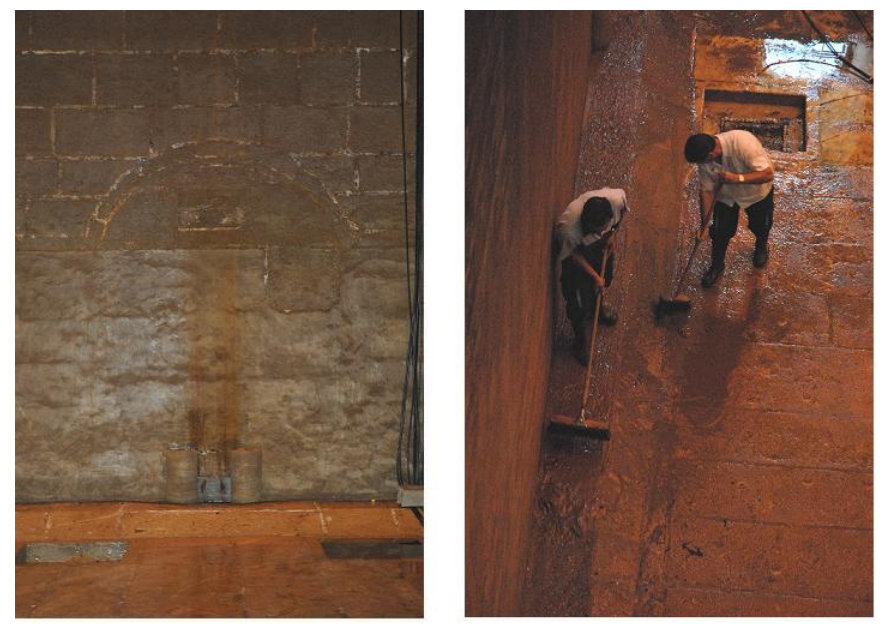

Figure 5: The tank is finally empty and the staff are cleaning and washing it.

The reduction of the aquifers provoked the consumption of water from greater deepness, generally salty and consequently of inferior quality. Therefore, the Regional Direction of the Environment and Natural Resources has forbidden the opening of new holes.

Deforestation has also damaged the superficial and underground waters. The safeguarding of the forest is critical for the stabilization of the drainage basins and of the respective hydrological regime. 


\section{Lisbon, a city facing the river Tagus}

Water can be captured in the hydrological cycle and, so, constitutes a natural renewable, delicate resource to be put at the disposal of Man. The medium annual precipitation of the national territory has been estimated at about $1000 \mathrm{~mm}$, being $370 \mathrm{~mm}$ referring to the superficial and subterranean escape. The remaining $630 \mathrm{~mm}$ is from the water that returned to the atmosphere by evaporation. The most important rivers that run in Portugal - Minho, Douro, Tagus and Guadiana have hydrological basins that are situated partially in Spanish territory. The Tagus River is born in the Albarracin Mountain, near the entrance to Portugal at Vila Velha de Rodão and after bathing Lisbon, drains into the Atlantic Ocean. The medium altitude of the hydrological Portuguese basin is at $300 \mathrm{~m}$, presenting several effluents, on both the borders. Recently, the natural regime of the river Tagus has changed and the flow coming from Spain was reduced due to the construction of big dams and to the increase of water consumption.
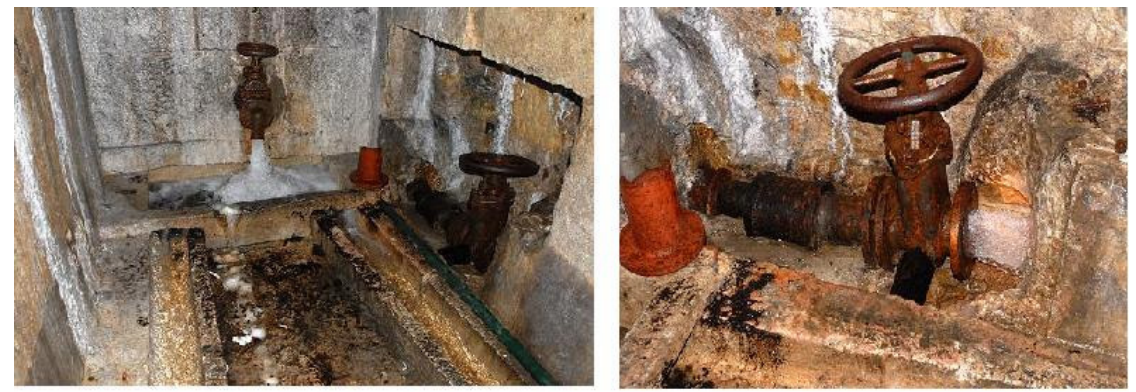

Figure 6: The stop-cock and the tap located in the underground gallery next to the periphery of the water tank.

The Portuguese basin is negatively affected not only by the poor quality of effluents from Spain, but also by its own domestic and industrial pollution. Thus, water for public utilization had to be treated (often by chlorine) to assure the elimination of microorganisms that threaten public health. As water demand continued to grow and water sources became more polluted, the simple sustainability paradigm underwent a change. On one hand, recognition that many diseases were water-borne helped to improve sanitation of urban centres. Pavements and sewers surveyed for the effective disposal of waste from the streets improved life conditions for many millions of people. The sanitary facilities built in the developed world in the 19th century had a significant impact on public health, a contribution often forgotten today.

The degradation of water resources of the international basins and its socioeconomical consequences resulted in a serious effort of the European Community to promote the protection and the utilization of the watercourses across national borders. To balance the deficient drainage of a waterway one appeals to the natural reserves - lakes, lagoons, or ponds. Faced with the 
increased necessity of consumption, it becomes indispensable that hydro resources be optimised through specific workmanship able to create alternative systems, such as wells, reservoirs, artificial reservoirs, canals, and water pumps. The continuing development of water purification technologies allowed the balancing of the water sources of different quality and availability. Sometimes, it was possible to bring clean water over long distances and avoid extensive treatment. As another option, local, less-clean water supplies could be used when enhanced by treatment using a variety of processes. Thus, the modified sustainability framework was to match water demand with available supplies in terms of both quantity and quality. As a single water supply system commonly provides water for different purposes (drinking, hygiene, irrigation, waste disposal), the quality of all supplied water was dictated by the most stringent requirements, most frequently those for potable water.

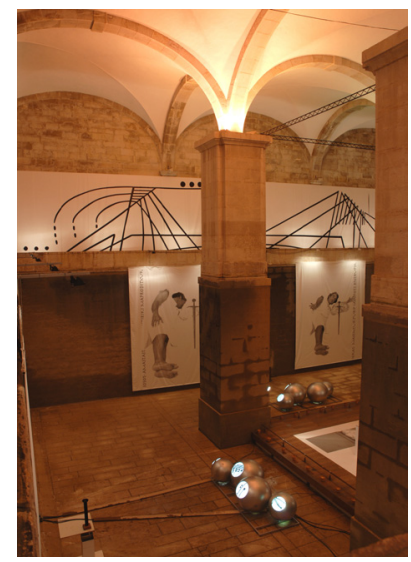

Figure 7: Manuel Carmo's installation in the corridor downstairs in the dry water tank.

\section{National program for the efficient use of the water}

It is indispensable to know the superficial and subterranean water resources, taking into account the cycle of the water, its quality and use. Water is a precious resource that needs a rational management plan, which reconciles, at the same time, the requests in short and long terms. It imposes a true politics in the domain of the water resources, which implies numerous studies about conservation, regularization and distribution plan. Beyond this, the conservation of the quality and quantity of the water requires the development and improvement of the techniques of utilization, of recycling and of purification [4].

The objective of this National Program is consequently to promote the efficient use of the water in Portugal, in the urban, agricultural and industrial sectors, and to minimize the risks of hydrological stress, both during periods with sufficient or insufficient supply of water. This program proposes the 
consolidation of a new water culture in Portugal, where this resource is increasingly valued not only for its importance for human and economic development, but also for the preservation of the natural concept of sustainable development. This Program has been elaborated based on the study "Efficient Use of the Water-Proposal of National Program", recently elaborated for the National Laboratory of Civil Engineering (LNEC) for the Water Institute (INAG), counting on the contribution of the Superior Institute of Agronomy (ISA).

Humanity has permitted the destruction of the natural cycles of life and of landscapes that are our precious natural and cultural heritages. Rivers are often the emblem of geographical localities and their local populations. We have been making the citizens aware of how important it is to defend and protect the rivers heritage; to recover the fluvial border zones; to save the watermills, and to revive the public uses of these nice areas for recreation.

\section{5 "The alchemy of water in the fine arts"}

While some artists showed a direct interest in water itself, such as Leonardo da Vinci, who was fascinated by water and studied it both as an artist, scientist and as hydrological engineer, others represented the many attributes of water conveyed literally, metaphorically, symbolically, or allegorically in mythology, and religion. One category of images can be grouped together under a title of Waters of Change. This happens because of the rich attributes and power of the water, as one of the four elements in our planet.

Art must have the ability to provoke, to stimulate, and to inspire. The mission of art is to develop in people the notion of thinking towards the future generation, and to explore new ideas and challenges to improve the world.

It was essential that the scientist, the hydrological engineer, and the ecologist, using scientific instruments and surveys the level, or quality of the water, and intensify our understanding of its ecological significance.

Also needed are artists on site, probing and recording the landscape with the camera and the palette. Not everyone responds in a scientific way to describing or evaluate the water crises, which the entire humanity is presently suffering. Many people are more stimulated by visual and aesthetic expressions of landscape and environment, than by calculations, or by measures ...

... "Manuel Carmo is full of conviction. He ignores the reminders of cultural specificity and does not fall into any category. It is impossible to disentangle the paintings /text / photography and design as they all blend into one, revealing the artist's gift for storytelling" [6].

As Gillian Goya [6] says in her article about Manuel do Carmo's work:

"The timing of "In Definition" - The Corridor of Water in Life, by the renowned artist Manuel Carmo could not be more apt. At Mãe D'Água Museum he sends you on a theatrical trip from birth until death and has transformed the Museum into a Water Divinity, a mediation on human life - where we are going where we would". 

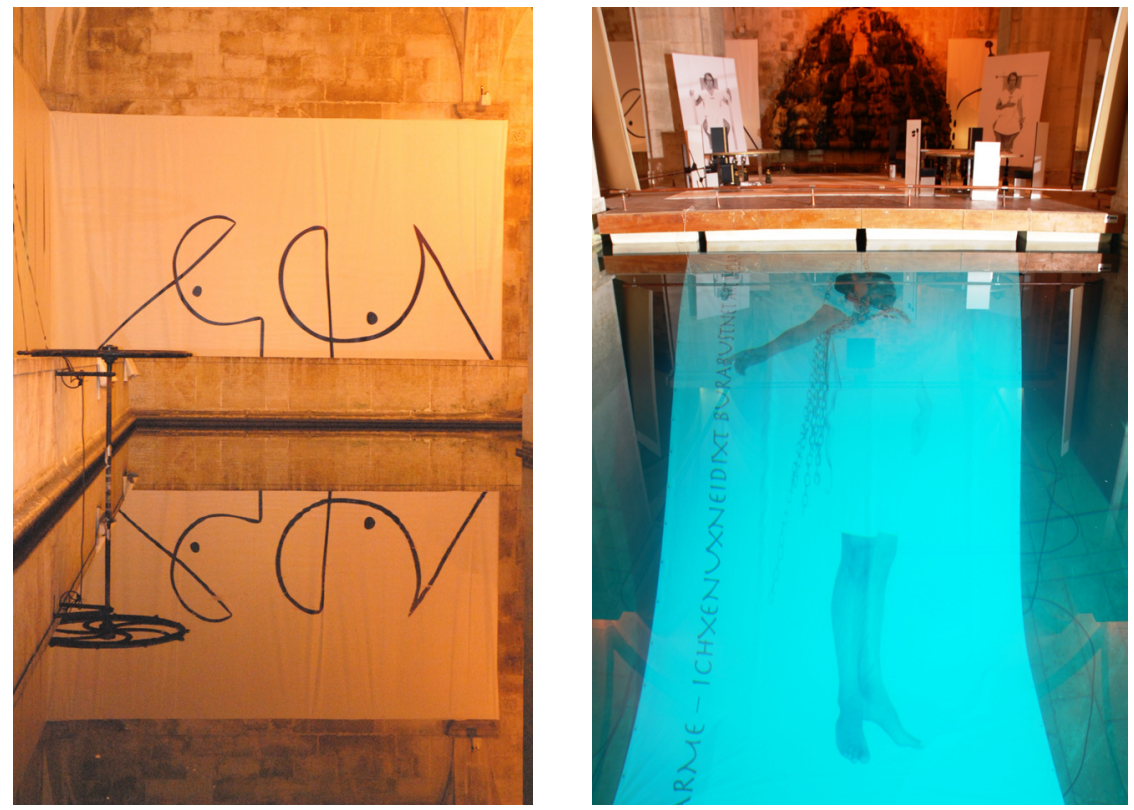

Figure 8: " $\quad$ "All things begin and end with water, our most essential element. All things flow from it, away from it and towards it. Thus begins and ends our Circle of Life." [5].

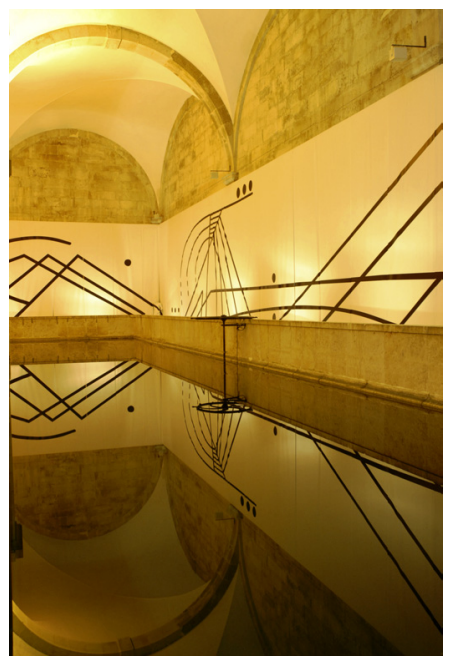

Figure 9: The Mother of Water returned to its usual condition, filled again with water. 


\section{References}

[1] d'Olanda, F.,Da fábrica que falece a cidade de Lisboa,Lisboa, 1571.

[2] Castilho, J., "Lisboa Antiga - Bairros Orientais" - Vol. IX e X - revista e ampliada pelo autor e com anotações do engenheiro Augusto Vieira da Silva, 2a edição C.M.L. 1937.

[3] Castelo-Branco, F., "Lisboa vista pelos estrangeiros - até aos fins do séc. XVIII”. Ed. Academia Portuguesa de História, Lisboa, 1982.

[4] Gleick, P., "Water in Crisis-A Guide to the World's Fresh Water Resources", Oxford University Press, UK, 1993.

[5] FYFE, Patricia - Words from an artist: She has studied a BFA from the University of Ottawa, and she has studied in the USA and Mexico.

[6] GOYA, Gillian is the International Curator of In-Definition Exhibition, 2007. 